\title{
Perspectives on gender parity in bioanalysis: an interview with Scott Summerfield
}

Scott G Summerfield ${ }^{*, 1}$

${ }^{1}$ Department of Bioanalysis, Immunogenicity \& Biomarkers, GlaxoSmithKline R\&D, Park Road, Ware, SG12 ODP, UK

*Author for correspondence: scott.g.summerfield@gsk.com

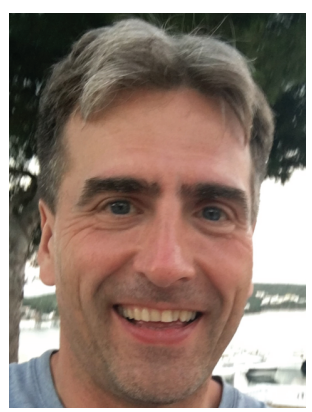

\section{Biography:}

Having studied for a PhD and postdoctoral fellowship in proteomics Scott moved into the field of regulated Bioanalysis in 1997 when joining SmithKline Beecham. In 2001, Scott moved to Neuroscience Drug Discovery to lead a bioanalytical team supporting PK, in vitro DMPK and metabolite id work. In 2009, he returned to the regulated bioanalytical group, initially as a Section Leader and subsequently as Site Head and currently as WW Head of Bioanalysis at GSK. Scott has experience of small and molecule bioanalysis as well as leading both bioanalytical and discovery and development project teams across GSK.

Accepted for publication: 13 March 2019; Published online: 18 April 2019

What advice would you give to young women hoping to embark on a career in the field?

Organizations value creativity, clarity of thought and how to deliver strategies by engaging the maximum number of people. Offer solutions to leaders not just the problem, and at last, be courageous, aim high and think big. If you believe you have the right skills then be proud of that. And if you do not feel listened to then remember you choose to work where you do, you always have the power to find an organization that is more forward thinking.

\section{How can mentors help women in their career development?}

Mentors are great for sharing their experiences, for example, "I've been there, and my advice is.. .". But coaching is particularly valuable to build self-belief "What would success look like for you and what would your steps be to get there?" This is an area where many people can psych themselves out, "Oh they are more assertive than I can ever be." It really is nonsense and women often bring a more rounded viewpoint than one focusing mostly on themselves.

\section{What advice would you give to women hoping to pursue senior-level scientific positions?}

Be honest and transparent in your development conversations about what you really want to achieve. Do not be afraid of seeking stretch opportunities that might take you into a different role. In the long run, breadth of knowledge is a significant aid to performing more senior roles.

What are the most valuable skill sets women/diversity bring to an organization?

Diversity of viewpoint is really important to making good decisions. This includes the more empathic and peoplecentric elements that women and many diversity candidates seem to appreciate more instinctively.

If you were asked to create a specific framework in your business to encourage more gender parity how will you do that?

The hiring process needs to provide a diverse selection of applicants for interview; otherwise, there is no choice at the get-go. For established employees, it is about building self-belief and releasing their potential, so tailored coaching programs are essential. Also, providing a transparent salary and remuneration structure that makes all employees feel that progression is based on talent and not some hidden biases. 


\section{How do you think the scientific field could inspire the next generation of scientists to} advocate gender parity?

Scientific abilities are equivalent and so the question is really what is attractive about a role or organization that is agnostic to gender; knowing an organization is transparent and is committed to a level playing field with respect to salary and growth opportunities, running internal programs (like coaching) that are available to anyone wishing to build their own capabilities, ensuring that every internal opportunity has a selection of candidates to select from that reflects diversity, celebrates success as an inspiration to other employees.

\section{Disclaimer}

The opinions expressed in this interview are those of the interviewee and do not necessarily reflect the views of Future Science Group.

\section{Financial \& competing interests disclosure}

The author has no relevant affiliations or financial involvement with any organization or entity with a financial interest in or financial conflict with the subject matter or materials discussed in the manuscript. This includes employment, consultancies, honoraria, stock ownership or options, expert testimony, grants or patents received or pending, or royalties.

No writing assistance was utilized in the production of this manuscript. 